\title{
PRINCÍPIOS DE CURADORIA DE RECURSOS DIGITAIS EM INGLÊS COMO SEGUNDA LÍNGUA NO ELO EM NUVEM
}

\author{
André Firpo Beviláqua ${ }^{1^{*}}$ \\ ${ }^{1}$ Universidade Federal de Pelotas, Pelotas, RS, Brasil
}

Vanessa Ribas Fialho ${ }^{3 * * *}$

${ }^{3}$ Universidade Federal de Santa Maria, Santa Maria, RS, Brasil

Vilson José Leffa ${ }^{1 * * * *}$

${ }^{1}$ Universidade Federal de Pelotas, Pelotas, RS, Brasil

\begin{abstract}
Resumo
Com ou sem conhecimento do conceito de curadoria, professores de Inglês como Segunda Língua lançam mão de inúmeras práticas de curadoria digital de material didático para o ensino de línguas. Tendo em vista que tais ações podem ser otimizadas por tecnologias on-line, sobretudo por Sistemas de Autoria Abertos, temos por objetivo analisar práticas de curadoria aplicadas ao sistema Ensino de Línguas Online (ELO) em Nuvem. Com o respaldo teórico de pesquisas sobre curadoria digital, desenvolvemos um estudo de natureza aplicada, com abordagem metodológica qualitativa, usando os cinco princípios de curadoria digital propostos por Deschaine e Sharma (2015): Coleção, Categorização, Crítica, Conceituação e Circulação. Os resultados indicam que o ELO incorpora os cinco princípios, embora alguns recursos e ferramentas do sistema para essa prática possam ser aperfeiçoados.

Palavras-chave: Curadoria Digital; Sistema de Autoria Aberto; ELO em Nuvem
\end{abstract}

\footnotetext{
Doutorando do Programa de Pós-Graduação em Letras da UFPel e acadêmico do curso de Letras Português EAD da UFSM. Integrante do GITEA, Grupo de Investigações sobre Tecnologias, Ensino e Aprendizagem (CNPq). E-mail: andre.firpo@gmail.com Orcid: https://orcid.org/0000-0002-3169-3474.

${ }^{* *}$ Doutor em Letras pela Universidade de Santa Cruz do Sul (UNISC). Atualmente, é professor no Instituto Federal do Paraná (campus Assis Chateaubriand). E-mail: alan.dan.ricardo@gmail.com Orcid: https://orcid. org/0000-0001-8132-6202.

${ }^{* * *}$ Doutora em Letras pela Universidade Católica de Pelotas (UCPel). Atualmente é Professora Associada do Departamento de Letras Estrangeiras Modernas (DLEM) da UFSM. Líder do GITEA, Grupo de Investigações sobre Tecnologias, Ensino e Aprendizagem (CNPq). E-mail: vanessafialho@gmail.com Orcid: https://orcid. org/0000-0002-4512-4256.

**** Doutor em Linguística Aplicada pela Universidade do Texas (EUA). Atualmente é professor visitante e pesquisador colaborador do Programa de Pós-Graduação em Letras da UFPel. Foi líder do grupo de pesquisa “Tecnologia e Aprendizagem de Línguas”(CNPq). E-mail: leffav@gmail.com Orcid: https://orcid.org/00000002-1605-5626.
} 


\title{
PRINCIPLES OF CURATION OF OPEN AUTHORING SYSTEMS OF ENGLISH AS A SECOND LANGUAGE IN ELECTRONIC LEARNING ORGANIZER
}

\begin{abstract}
With or without knowledge of what content curation means, teachers of English as a Second Language make use of numerous digital curation practices of teaching materials for language teaching. Bearing in mind that such actions can be optimized by online technologies, especially by Open Authoring Systems, we aim to analyze curatorial practices as applied to the Electronic Learning Organizer (ELO) Cloud, a free-access cloud authoring tool available for language teachers. With the theoretical support of research on digital curation, we developed a study of an applied nature, with qualitative orientation, using the five principles of digital curation as proposed by Deschaine and Sharma (2015): collection, categorization, critiquing, conceptualization and circulation. The results indicate that ELO incorporates the five principles, although some resources and tools for this practice can be improved.

Keywords: Digital Curation; Open Authoring Systems; ELO Cloud
\end{abstract}




\section{Introdução}

A curadoria de materiais digitais para o ensino de línguas é um tópico emergente na seara da Linguística Aplicada (LA) hoje. Tal fenômeno é comprovado pela literatura da área, seja em âmbito nacional (ARAÚJO, 2019; SILVA, 2019), seja em âmbito internacional (ZHANG, 2015; CEPEDA; HORTIALES; ROMERO; 2016).

O referido interesse se justifica pela correlação entre o processo de curadoria e as muitas práticas que o professor de línguas já efetua em seu trabalho docente na atualidade, como: (a) busca e seleção de recursos didáticos em portais educacionais e repositórios virtuais, (b) análise e adaptação de materiais de acordo com os objetivos e interesses de seus estudantes e de seu contexto de atuação docente; e (c) organização de materiais em módulos e atividades que orientem a aprendizagem de línguas, entre outras práticas.

Cabe frisar, ainda, que o contexto de pandemia vivenciado a partir de 2020, em função do novo coronavírus (SARS-CoV-2), que resultou na implementação do Ensino Remoto Emergencial (ERE) em muitas instituições de ensino no Brasil e no mundo, também contribuiu para a disseminação de práticas de curadoria entre os docentes. Inúmeros professores de línguas, ao longo de 2020, ano 1 da pandemia do coronavírus, lançaram mão de práticas de curadoria, buscando, selecionando, adaptando e organizando recursos digitais com o intuito de migrar para o ensino online. Nesse viés, inclusive, um pressuposto sobre o qual o presente trabalho está alicerçado é: muitos professores de Inglês como Segunda Língua (IL2) já atuam como curadores, ou operam práticas de curadoria de material didático digital, embora talvez não estejam cientes disso.

Um segundo pressuposto subjacente a este estudo, e em conexão com o primeiro, é concernente ao conhecimento que os professores necessitam possuir sobre práticas de curadoria. Apesar de concordarmos com a indiscutível importância da formação docente para práticas de (co)produção (OKADA, 2014) e adaptação de materiais didáticos para o ensino de IL2, não defendemos nem que os professores precisam de conhecimentos teóricos profundos sobre os princípios e modelos de técnicas de curadoria, nem que curadores especialistas devam fazer esse trabalho de seleção, análise e organização de materiais para o professor. Em contrapartida, coadunamos da opinião de que o professor deve atuar como seu próprio curador, assim como os muitos artistas plásticos que atuam como curadores de seus próprios trabalhos (MOURA, 2013). E, para tanto, o docente não precisa de conhecimentos teóricos nem maiores nem menores do que aqueles necessários para um profícuo ensino de IL2 mediado por materiais didáticos digitais. Ao professor, deve caber todo o trabalho referente às etapas de (1) análise, (2) desenvolvimento, (3) implementação e (4) avaliação de recursos didáticos - processo que Leffa (2008a, p. 16) intitula "ciclo recursivo de produção de materiais para o ensino de línguas". Aqueles conhecimentos teóricos específicos concernentes à curadoria que podem ser otimizados pela tecnologia, em nosso entendimento, devem ser otimizados pela tecnologia, não só porque, na 
essência, a tecnologia per se serve para contribuir com nossas práticas humanas, mas também em razão da tendência atual de enriquecimento das práticas educacionais com e por meio das tecnologias digitais. A exemplo disso, podemos aludir aos repositórios digitais e portais educacionais online que, na opinião de Santos $(2011$; 2013), devem facilitar a vida do professor, padronizando licenças de abertura, uso, adaptação e compartilhamento de recursos digitais, evitando, assim, que o docente invista tempo desnecessário no árduo trabalho de saber o que pode ou não fazer com o que encontra na internet.

Diante de todo o exposto, questionamo-nos sobre a aplicabilidade de diferentes modelos teóricos e taxonômicos de curadoria digital já propostos e compartilhados no meio acadêmico. Algumas das questões norteadoras que nos movem enquanto pesquisadores, portanto, são: (1) Portais educacionais e repositórios online de materiais para o ensino de IL2, atualmente, contribuem e favorecem as possíveis práticas de curadoria de professores? (2) Repositórios e portais educacionais digitais estão em sinergia, por exemplo, com o modelo teórico de práticas de curadoria de Deschaine e Sharma (2015), um dos mais referenciados na academia atualmente? (3) As etapas de coleta, categorização, crítica, conceituação e circulação - pilares do processo de curadoria para Deschaine e Sharma (2015) - podem ser efetivadas e facilitadas por recursos tecnológicos tais quais repositórios de materiais didáticos digitais, portais educacionais e ferramentas de autoria para o professor?

Nosso objetivo geral, portanto, é analisar as práticas de curadoria aplicadas ao sistema Ensino de Línguas Online (ELO) em Nuvem. As justificativas para a escolha de tal ferramenta são: o ELO é um sistema desenvolvido por e para professores de línguas (COSTA, 2016); tal sistema encontra-se disponível na web de forma aberta e gratuita; e, segundo estudos recentes, o ELO é um dos sistemas favoritos na opinião de professores de línguas (FONTANA; FIALHO, 2013; COSTA; BORSETTI; GABRIEL, 2021). Já os objetivos específicos deste estudo são três: (1) verificar a aplicabilidade dos 5 C's da curadoria digital (DESCHAINE; SHARMA, 2015) no ELO em Nuvem; (2) averiguar potencialidades do ELO para facilitar a curadoria digital por parte do professor de IL2; e (3) propor aprimoramentos e melhorias do sistema em questão no que tange à facilitação e otimização de práticas de curadoria entre docentes.

Este artigo está organizado em cinco seções, sendo a primeira esta introdução. Na segunda seção, apresentamos uma breve revisão da literatura sobre o ELO em Nuvem e suas potencialidades atuais para as práticas de desenvolvimento de materiais e atividades para o ensino de línguas. Na terceira seção, debruçamo-nos sobre algumas questões pertinentes ao conceito de curadoria digital, com base em estudos recentes na área de LA. Na quarta seção, apresentamos a metodologia deste estudo, para, na quinta seção, apresentar nossas análises do sistema ELO em Nuvem no que tange aos 5 C's da curadoria, isto é, aos processos de coleta, categorização, crítica, conceituação e circulação de recursos para o ensino de IL2. Finalmente, apresentamos nossas considerações finais, reiterando não só a importância das práticas de curadoria digital na atualidade, mas também da 
distribuição desses processos entre tecnologias digitais e outros agentes, como professores e aprendizes de línguas.

\section{O ELO em Nuvem como Sistema de Autoria e de Curadoria}

O sistema ELO foi originalmente concebido como uma Ferramenta de Autoria (VÍRSIDA, 2006; PAIVA, 2012), ou, como prefere Leffa (2006b), uma Ferramenta de Autoria para o Professor (FAP), alternativa que salienta o papel do docente, fundamental no processo de elaboração de atividades e materiais didáticos para o ensino de línguas. Segundo Costa (2016), ainda que uma Ferramenta de Autoria possa ser (e geralmente é) usada por um técnico ou um programador, em termos pedagógicos, interessa mais o trabalho do professor no ensino de línguas, e a opção por debater as FAPs, nesse viés, contribui de forma mais específica com a comunidade docente.

Em apertada síntese, uma FAP é um programa de computador usado para a produção de arquivos digitais, geralmente incluindo texto escrito, imagem, som e vídeo (LEFFA, 2006b). Trata-se de um software que visa a auxiliar o professor na produção de materiais e recursos educacionais, no sentido de poupá-lo do trabalho mais técnico de manipulação de linguagens de informática, destinado ao programador. Nas palavras de Leffa (2006b, p. 193): "Não se trata de substituir o professor, mas de ampliar sua ação através da máquina”.

Em sua primeira versão, a FAP, outrora designada apenas como ELO, consistia em um software a ser baixado e instalado em um computador e, a partir de então, possibilitar a produção de materiais e atividades off-line naquela máquina especificamente. Em 2011, uma segunda versão do ELO foi lançada, totalmente on-line, o que justifica seu novo epíteto: "em Nuvem" (https://www. elo.pro.br/cloud/index.php). Nessa nova versão, as potencialidades do ELO se expandiram em rede: professores de diferentes regiões podiam criar seu perfil on-line no sistema, de forma muito semelhante ao que ocorre em sites de redes sociais (como o Twitter) e, então, produzirem atividades digitais para o ensino de línguas, que poderiam ser disponibilizadas em um grande repositório virtual.

Nesse repositório em nuvem, um docente pode buscar materiais e recursos elaborados ou desenvolvidos por seus pares e, ao importá-los para si, pode também adaptá-los segundo suas necessidades. Essa adaptação não se dá no material original, mas em cópias importadas, que preservam intacta a primeira versão e permitem a modificação das novas versões daquela atividade ou módulo (BEVILÁQUA et al., 2017). Em outras palavras, os materiais do ELO não funcionam na lógica da Wikipédia, cujo conteúdo é o mesmo para todos e sofre modificação na direção "de um para todos". No ELO em Nuvem, cada professor importa o material para si, na direção "de todos para um", e, a partir disso, adapta e modifica uma duplicata do conteúdo original desenvolvido por outro professor de línguas.

À medida que o ELO em Nuvem avançava como objeto de estudo, contexto de pesquisa ou instrumento metodológico de inúmeras investigações 
em LA na última década (e.g. IRALA, 2012; COSTA, 2016; CANTO, 2016; BEVILÁQUA, 2017; entre outros), se popularizavam no Brasil as iniciativas de REA, sigla para Recursos Educacionais Abertos (REA). Segundo definição consolidada em consórcios da UNESCO (2012), um REA é um material de ensino, aprendizagem e/ou investigação em qualquer suporte, digital ou outro, e situado em domínio público ou divulgado com licença aberta que permite seu acesso, uso, adaptação e redistribuição de forma gratuita por terceiros, mediante nenhuma ou pouca restrição.

Nobre e Mallmann (2016, p. 153) apontam que não há consenso sobre a finalidade, a profundidade, a estrutura ou visão tecnológica para criar, reutilizar, reprogramar e "repartilhar" os REA, porém, apesar disso, eles ainda representam para a educação uma "promessa" de melhoria, por serem materiais que comportam uma variedade de benefícios, como a maior contextualização a partir de particularidades de cada contexto de ensino e de aprendizagem. A elaboração e a disponibilização de REA e cursos abertos e a consequente expansão e democratização do acesso ao conhecimento seria um desses principais benefícios, mas outros podem ser elencados, como a possibilidade de participação efetiva, por parte dos agentes educacionais, na produção de conhecimento, "tanto para resolução de problemas locais, quanto para ampliação do campo cognitivo da humanidade em larga escala" (NOBRE; MALLMANN, 2016, p. 153).

Alguns trabalhos iniciais sinalizaram as semelhanças entre os materiais armazenados e disponíveis no ELO em Nuvem e a proposta teórica dos REA (LEFFA, 2016; COSTA, 2016), o que levou à proposição do conceito de Sistema de Autoria Aberto (SAA), por parte de Beviláqua et al. (2017). Em suma, um SAA é um sistema online e gratuito que, com base na filosofia de abertura dos REA, facilita a produção, a adaptação e o licenciamento dos referidos recursos.

A pesquisa que funda o conceito de SAA no âmbito acadêmico (BEVILÁQUA et al., 2017) parte da análise do ELO em Nuvem no que concerne à possibilidade de Reusar, Revisar, Remixar e Redistribuir os REA para o ensino de línguas. Esses 4 R's referentes aos REA foram propostos por Hilton et al. (2010) para pensar os níveis de abertura que um recurso pode apresentar, para além das licenças do material. Tais níveis podem ser resumidos da seguinte forma: (1) Reutilizar: nível de abertura que possibilita a reutilização total ou parcial do REA, como o caso, por exemplo, de um docente que reproduz uma entrevista - ou uma parte dela -, em uma atividade de compreensão oral em língua estrangeira; (2) Revisar: nível de abertura que possibilita pequenas adaptações no REA, como a reformulação da instrução de uma atividade, ou alteração de uma imagem ou figura que componha o material; (3) Remixar: nível de abertura que viabiliza a combinação de diferentes recursos, como no caso de uma atividade em que estão reunidos vídeos, músicas, textos escritos e fragmentos de outros materiais em um mesmo REA; e (4) Redistribuir: nível de abertura relacionado ao compartilhamento do REA com terceiros.

Mais recentemente - e considerando que as práticas de curadoria não apenas contemplam, mas vão muito além das práticas de Reuso, Revisão, Remixagem e 
Redistribuição de REA - questionamo-nos sobre os 5 C's da curadoria aplicados ao ELO em Nuvem, ou contemplados indiretamente nele. Cabe avaliar, pois, se o ELO em Nuvem é também um sistema que possibilita e potencializa as práticas de curadoria digital de professores de IL2; e, se sim, em quais aspectos e em que medida essas práticas de curadoria se efetivam.

\section{Curadoria Digital: Uma Proposta}

É difícil afirmar a origem do conceito de curadoria, uma vez que o termo, ao longo dos séculos, foi adquirindo diferentes significados, a depender de cada contexto sócio-histórico e/ou campo de conhecimento. Do ponto de vista etimológico, trata-se de uma palavra latina, curare, que significa cuidar ou preservar (CORREIA, 2018). Por aproximação, um curador seria "aquele que cuida", e, com efeito, em áreas como o Direito, o termo curadoria é utilizado para designar o papel de pessoas incumbidas, judicialmente, pelo cuidado de terceiros.

Segundo Araújo (2019), em meados do século XX, o termo ficou amplamente conhecido no campo das Artes, para fazer referência aos profissionais encarregados pela manutenção das obras e pela organização das exposições artísticas, levando em consideração diferentes objetivos e/ou finalidades: temáticas, históricas, didáticas, entre outros. Nesse contexto, cabia aos curadores a seleção e a avaliação criteriosa das obras de arte expostas, o que acabou conduzindo a níveis cada vez mais elevados de exigência e expertise desses profissionais (BINI, 2005).

$\mathrm{Na}$ atualidade, a separação rigorosa dos papéis de artista e de curador tem sido bastante questionada no campo das Artes. Trabalhos como o de Moura (2013) demonstram que dois artistas com trajetórias diferentes, tanto no que diz respeito à produção artística quanto no que se refere à atividade curatorial, podem discordar com relação à separação categórica desses papéis, conforme vemos a seguir:

Maneschy aponta que é possível a distinção entre o trabalho do artista e o fazer curatorial, já que para ele a pessoa que se propõe a curar exposições tem que saber lidar com questões de ética e, a partir das suas experiências, buscar outros caminhos que complementem e enriqueçam seu trabalho em curadoria. Enquanto que Queiroz nos aponta um caminho de maior fluidez entre as funções (artista-curador/curador-artista), no qual as trocas são partes fundamentais na multiplicação das interconexões efetivadas neste campo de atuação, aumentando as possibilidades de redefinição dos papéis, não que este prescinda da ética, mas Queiroz sente-se mais à vontade com a mistura dos papéis. (MOURA, 2013, p. 398).

Como é possível perceber no fragmento acima, há artistas que percebem uma separação nítida entre o fazer artístico e o fazer curatorial, ao passo que outros observam maior fluidez entre esses dois papéis (artista-curador/curadorartista). Ambas as compreensões são importantes para a discussão que propomos sobre a curadoria digital no campo da LA.

Devido ao turbilhão de informações disponíveis no ciberespaço, uma questão que, inevitavelmente, acaba surgindo, diz respeito ao modo como 
selecionamos, avaliamos e organizamos todos esses conteúdos. É nesse cenário que o conceito de curadoria digital tem despertado o interesse de outras áreas que não apenas a das Artes, como a da Comunicação, a da Engenharia de Computação e a da LA, entre outras.

No âmbito da LA e, mais especificamente, do ensino de IL2, interessanos pensar de que forma o conceito de curadoria digital pode nos auxiliar com questões como: Onde encontramos REA para o ensino de línguas? Como selecionamos esses materiais a partir de nossas necessidades específicas? Será que esses recursos realmente foram disponibilizados com uma licença de uso aberta? Há como saber se passaram por algum tipo de análise prévia? Como reorganizar e remixar esses conteúdos a partir de nossas demandas locais? São questionamentos dessa natureza que temos aventado nos últimos anos, e para os quais os estudos sobre curadoria podem apresentar importantes contribuições.

Um exemplo prático da importância de tais questões é o compartilhamento de atividades criadas por professores de línguas durante a pandemia da Covid-19 em grupos de Facebook. Nesses espaços, docentes de diferentes regiões socializam materiais de sua própria autoria, na intenção de que outros professores - tanto "autores" quanto "não autores" - também pudessem usufruir dessas produções. Embora esses grupos apresentem inúmeros aspectos positivos, como a colaboração em massa (FIALHO, 2011), o compartilhamento de atividades autorais e o intercâmbio de ideias sobre esses conteúdos, destacamos algumas questões que, da nossa perspectiva, dificultam o trabalho do professor nesse contexto: (1) Não há um sistema de metadados que facilite a busca e/ou recuperabilidade ${ }^{1}$ desses materiais a partir de necessidades específicas (por exemplo, "língua", "tema”, "conteúdo", "nível de ensino", entre outros); (2) Na maioria das vezes, há poucas informações sobre as atividades apresentadas, o que faz com que os docentes interessados precisem baixá-las para um exame mais minucioso, ou seja: falta uma explicação sobre o contexto para o qual cada atividade foi pensada, o objetivo desse material, a concepção de linguagem subjacente a essa proposta, entre outros aspectos); (3) As atividades são disponibilizadas ao longo de um extenso feed de conteúdos vertical e não permanecem na ordem cronológica de publicação. Se o docente quiser saber se esses materiais foram disponibilizados recentemente ou há mais tempo, precisará conferir a data de cada publicação individualmente.

No presente artigo, diferentemente do que temos observado em algumas pesquisas sobre curadoria digital (DESCHAINE; SHARMA, 2015), entendemos que os processos de natureza curatorial podem ser - e frequentemente o são realizados pelo próprio professor, de forma análoga ao artista que organiza suas próprias exposições. Da nossa perspectiva, propostas que atribuem a curadoria digital a um "especialista" não parecem adequadas, uma vez que remetem a dicotomias do tipo "teoria vs. prática", "especialista vs. não especialista", "professor universitário vs. professor de escola" ou "pesquisador $v s$. professor", das quais discordamos em absoluto (a esse respeito, sugerimos a leitura de FREIRE, 2016; LEFFA, 2008b). 
Também não é nossa intenção imputar mais atribuições ao professor, deixando-o mais sobrecarregado do que ele frequentemente está. Nosso propósito é justamente o contrário: demonstrar, desde uma perspectiva aplicada, de que forma a curadoria, por meio de tecnologias digitais, pode auxiliar no cotidiano docente, especialmente no que tange à seleção e à avaliação de recursos on-line e REA.

Tendo em mente o atual avanço tecnológico, que reflete também no aprimoramento de portais educacionais e repositórios digitais de materiais didáticos, presumimos que alguns processos de curadoria podem ser realizados pelo próprio professor, com base em subsídios fornecidos por agentes humanos e não humanos. Em outras palavras, estamos propondo uma espécie de curadoria em rede na qual o professor poderá contar com a colaboração de diversos elementos: sistema de metadados, algoritmos e, entre outros aspectos, avaliações de indivíduos implicados nos processos de ensino e de aprendizagem, sejam os alunos, sejam os colegas professores de línguas que utilizaram ou testaram a atividade.

Rigorosamente, o ideal seria reunir um pouco do que vemos em diferentes plataformas, por exemplo: na televisão por streaming, nossos algoritmos identificam que temos preferência por um determinado gênero de filme ou série; em sites de reserva de hospedagem, temos condições não apenas de filtrar acomodações que venham ao encontro de nossas expectativas, mas também de verificar comentários e avaliações de outros usuários. Esse conjunto de fatores, se aplicados às plataformas de (co)produção de materiais digitais para o ensino de línguas, pode facilitar de forma significativa a atividade docente.

Cumpre destacar, ainda, que nossa proposta difere um pouco da noção de professor-curador apresentada em Araújo (2019), com base na análise da plataforma Currículo+ (https://curriculomais.educacao.sp.gov.br/). Nessa plataforma, existe uma equipe de professores responsáveis pela curadoria dos materiais (id. ibid.), ao passo que, da nossa perspectiva, todo professor pode ser um curador. Para nós, a questão é como podemos fazer para tornar esse processo menos centralizado e individual, e mais rizomático (Sobre esse tópico, ver Costa (2016)) e colaborativo, a fim de enriquecer o trabalho docente. Como é possível observar, trata-se de uma proposta de fluidez da curadoria de material didático digital, sob o prisma da descentralização, da colaboração e da otimização daquilo que um docente de IL2 pode fazer com o respaldo da tecnologia e de outros agentes humanos.

Entendemos, também, que a curadoria digital, quando não analisada sob múltiplas perspectivas, tende a falhar em algum aspecto. Conforme aponta Araújo (2019), quando a curadoria for realizada estritamente por algoritmos, por exemplo, poderá incorrer na criação de "filtros-bolha" informacionais (PARISER, 2011), algo semelhante ao "Dilema das Redes" (The Social Dilemma, ORLOWSKI, 2020) aplicado ao universo de produção de material didático em rede do professor. Por isso, não defendemos a hierarquização entre os múltiplos agentes de curadoria, mas a sua associação e mútua complementação. 
Para finalizar a presente seção, caberia destacar os cinco princípios da curadoria propostos por Deschaine e Sharma (2015), já mencionados. Apesar de não concordarmos com a opinião dos autores quanto à visão de curador como um "docente da Universidade", entendemos que os princípios indicados em sua pesquisa podem auxiliar na compreensão dos processos de curadoria. Ademais, tais perspectivas teóricas podem ser alargadas e expandidas de modo a contribuir para a reflexão do que temos e do que podemos ter em repositórios de recursos digitais, portais educacionais e SAA para a (co)produção de REA, conforme propomos na seção de análises deste artigo. Para tanto, partimos dos 5 C’s da curadoria, de acordo com Deschaine e Sharma (2015): (1) coleção: a ênfase dessa etapa está na coleta e na catalogação de materiais; (2) categorização: nessa fase, a principal preocupação é a comparação dos itens coletados, a fim de "identificar aspectos da coleção que tornam esses itens mutuamente importantes e coesos" (DESCHAINE; SHARMA, 2015, p. 22); (3) crítica: nessa etapa, o foco está na avaliação criteriosa dos materiais, a partir da qual será possível encontrar justificativas para a inclusão ou para a exclusão dos itens previamente selecionados, com base em dados e pesquisas sobre o assunto; (4) conceituação: nesse estágio, o professor reorganiza os itens selecionados, estabelecendo conexões entre eles; e (5) circulação: nessa fase, o professor socializa suas coleções em plataformas da internet, preferencialmente abertas e gratuitas, em nossa opinião.

Entendemos que essa taxonomia de $5 \mathrm{C}$ 's do processo de curadoria, de Deschaine e Sharma (2015), pode representar um excelente ponto de partida para refletir sobre curadoria digital em uma perspectiva aplicada, contanto que sejam entendidas de forma interdependente, e não como categorias rígidas ou estanques. Isso quer dizer que partir desses princípios não significa, necessariamente, que ficaremos restritos a eles, visto que algumas etapas da curadoria digital podem ser incluídas ou excluídas, a depender das perspectivas teóricas e práticas que embasam o conceito de curadoria de cada professor-curador.

\section{Metodologia}

Desenvolvemos a presente pesquisa, de natureza aplicada, a partir de uma abordagem metodológica qualitativa. Para Paiva (2019, p. 11), no que concerne à natureza, a pesquisa é categorizada como aplicada quando "tem por objetivo gerar novos conhecimentos" e, como meta, "resolver problemas, inovar ou desenvolver novos processos e tecnologias". No que diz respeito à abordagem metodológica, a pesquisa qualitativa é aquela que acontece no mundo real com o propósito de "compreender, descrever e, algumas vezes, explicar fenômenos sociais a partir de seu interior, de diferentes formas" (FLICK, 2007, apud PAIVA, 2019, p. 13). Dentre outras, tais formas incluem análises de experiências (individuais ou coletivas), de interações e de documentos, como textos, imagens ou filmes (PAIVA, 2019).

Como procedimento metodológico, optamos por explorar o ELO em Nuvem, tentando realizar práticas de coleção, categorização, crítica, conceituação e circulação de recursos para o ensino de IL2. Ao passo que essas práticas iam 
sendo implementadas, a cada tentativa, analisávamos os recursos, as ferramentas, as potencialidades e as alternativas de aprimoramento do sistema ELO. Nossa navegação pelo SAA e interpretação de dados foi pautada pelo seguinte sujeito de pesquisa: um professor de IL2 buscando recursos e atividades para uma aula de inglês a partir de dois temas indicados na Base Nacional Comum Curricular - BNCC (BRASIL, 2018) - para o ensino de Língua Inglesa, no $6^{\circ}$ ano do Ensino Fundamental: simple present e to be verb. Tal percurso foi realizado de forma prática por um dos autores do presente artigo, com formação para atuar como docente de língua inglesa, e registrado em diários de bordo, para posterior discussão e análise com os demais autores.

Ainda quantoaos procedimentos metodológicos, cabe elucidar:interpretamos que o ELO permite que professores atuem como autores e/ou coautores. Como autor, ou "produtor", temos aquele professor que produz sua atividade original e disponibiliza para os demais docentes que queiram se apropriar daquele conteúdo. Como coautor, ou "coprodutor", temos aquele docente que entra no repositório de atividades do ELO com a intenção de aproveitar atividades já prontas e disponíveis de forma aberta. Ambos, para suas atividades, valem-se de práticas curatoriais, inclusive o professor autor, haja vista que produzir uma atividade no ELO implica selecionar, criticar, organizar e adaptar conteúdos digitais. Para esta pesquisa, optamos por analisar o caso de um professor de IL2 coautor, ou coprodutor, interessado em fazer uso de atividades já elaboradas e disponibilizadas por outros.

\section{A Curadoria na Prática: Análises do ELO em Nuvem}

A partir do que foi delineado até aqui, dividimos as análises e os resultados em dois momentos. Primeiramente, apresentamos o percurso de um professor de IL2, coautor do presente trabalho, explorando o ELO e efetivando práticas de seleção de materiais para o ensino de inglês no Ensino Fundamental. Em um segundo momento, retomamos os cinco princípios de curadoria digital, de Deschaine e Sharma (2015), a fim de analisar se as práticas realizadas na plataforma ELO (apresentadas na seção anterior) correspondem, e em que medida, às práticas de curadoria digital.

\subsection{Um Caminho Percorrido a Partir do Diário de Bordo de um Professor de IL2}

Ao ingressar na plataforma ELO, deparei-me $e^{2}$ com diferentes opções de acesso: como Professor, como Estudante e como Visitante. O Professor é aquele que trabalhará na (co)produção de atividades, buscando, desenvolvendo, adaptando e/ou organizando recursos variados. O Estudante é aquele que usufruirá das atividades elaboradas pelo Professor e disponíveis no ELO em Nuvem; tal Estudante também pode operar na busca, seleção e organização de materiais, evidentemente, para efetuar sua aprendizagem autônoma de IL2, a 
partir de um plano de estudo próprio que ele mesmo possa ter desenvolvido. Embora tal Estudante possa filtrar e escolher materiais, o foco, aqui, recai sobre as práticas de seleção de materiais do Professor. Finalmente, vejo o Visitante como aquele usuário que está apenas interessado em observar alguns recursos e conhecer o repositório de REA do ELO em Nuvem, sem necessariamente efetivar um ingresso como Professor ou Estudante.

O primeiro ponto a chamar minha atenção em meu percurso é a diferença de descritores e metadados para a busca de atividades e REA por parte de um Professor e de um Estudante. Essa busca pode ser otimizada a partir de descritores e metadados, que funcionam de modo análogo a um sistema de catalogação para encontrar, de forma mais eficaz, um livro em uma grande biblioteca. O Professor que busca somente materiais em inglês (descritor "Língua") de nível básico (descritor "Nível de dificuldade"), a modo de ilustração, pode valer-se desses metadados para facilitar as buscas e peneirar os resultados que o sistema lhe apresentará.

Todavia, conforme exposto na Figura 1, os descritores e metadados visíveis para o Professor, no momento de importar um recurso desenvolvido por outro docente, não são os mesmos visíveis para o Estudante. Enquanto Professor, posso efetuar buscas orientadas pelo "Tipo" (de recurso, se um vídeo, um jogo da memória, entre outros), pelo "Autor" (professor que produziu a atividade) ou pelo "Título" de um determinado material. Em contrapartida, como Estudante, posso efetuar buscas orientadas pelo título ou conteúdo (ou outras informações, todas possíveis de serem inseridas em "Buscar atividade"), pelo "Autor", pela "Língua ou área", pela "Faixa etária" (crianças, jovens, adultos ou todas), pelo "Nível de dificuldade" (fácil, médio ou difícil), pelo nome de um "Curso" no qual o recurso pode estar inserido e, inclusive, pelo tipo de apresentação da atividade para os aprendizes, se gamificada ou não ${ }^{3}$.

Figura 1: Opções de descritores para a busca, para o professor (acima) e para o estudante (abaixo)

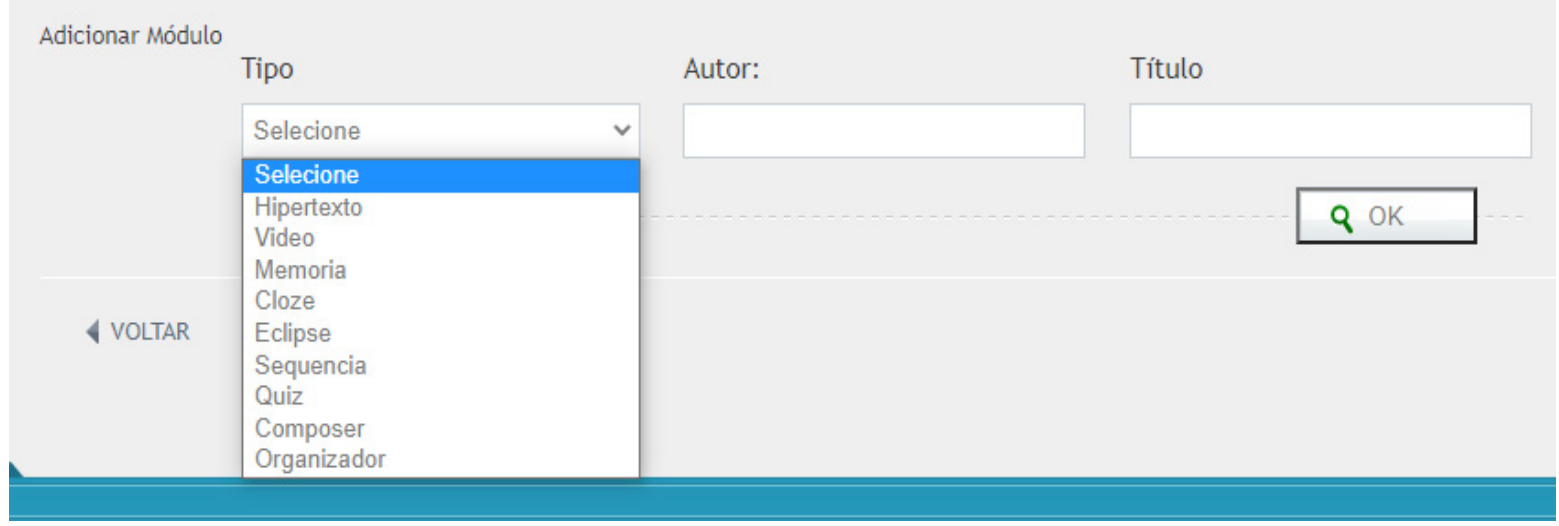




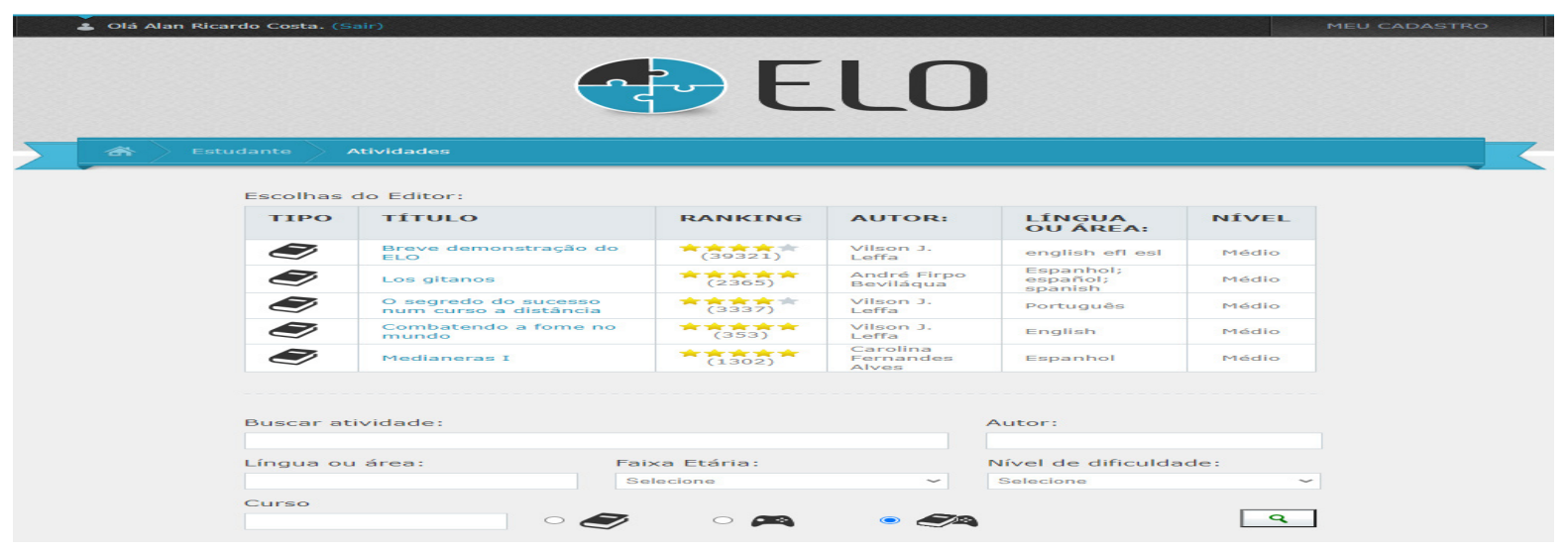

Fonte: Os Autores (2021).

Em um primeiro momento, interpreto como mais profícuos os descritores e os metadados ao alcance do Estudante que aqueles ofertados ao Professor. Em meu entendimento, ao Professor deveriam ser mantidas as opções de descritores e de metadados já ofertadas e, ainda, aquelas que estão ao alcance do Estudante, pois o processo de coleta de recursos por parte do docente deve ser o mais refinado possível, visando ao aprimoramento do trabalho pedagógico de (co)produção de uma atividade. Assim, vejo como alternativa para o Professor a criação de um perfil também como Estudante, para facilitar o trabalho de seleção de REA.

Superada essa primeira questão, meu percurso seguiu-se com o uso concomitante de dois perfis (Professor e Estudante), cada um em uma janela do computador. Realizei a busca por recursos e materiais a partir do primeiro conteúdo, simple present, fazendo uso do campo "Buscar atividades". Com essa busca, identifiquei um total de 14 REA no banco de atividades do ELO. Após essa seleção inicial, com a ajuda dos descritores "nível” (fácil) e "faixa etária" (jovens), foi possível refinar os resultados, levando em consideração meus objetivos (ensino de Língua Inglesa no $6^{\circ}$ ano do Ensino Fundamental). Restaram, dessa segunda seleção, 5 materiais sobre o tópico em questão. No que diz respeito ao segundo conteúdo, to be verb, repeti o mesmo processo: comecei por uma consulta mais geral ("Buscar atividades") e, logo, aprimorei a busca a partir dos descritores "nível” (fácil) e "faixa etária" (jovens). Localizei 23 REA na primeira consulta e 1 na segunda.

Na sequência, notei que os resultados das buscas, no perfil de Estudante, são apresentados a partir de um sistema de ranking que considera a avaliação por atribuição de notas (estrelas, de 0 a 5, como ocorre no popular app de trânsito Uber) e número de visualizações por parte de outros usuários. Na Figura 2, mostro a forma como esse ranking aparece para o Estudante. 
Figura 2: Ranking de atividades, por avaliação de usuários e número de visualizações

Favoritas:

\begin{tabular}{|c|c|c|c|c|c|}
\hline TIPO & TÍTULO & RANKING & AUTOR: & $\begin{array}{l}\text { LÍNGUA } \\
\text { OU } \\
\text { ÁREA: }\end{array}$ & NÍVEL \\
\hline & $\begin{array}{l}\text { Verb To be } \\
\text { Simple Past }\end{array}$ & 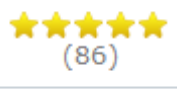 & Renata Hounsell & English & Fácil \\
\hline & $\begin{array}{l}\text { SIMPLE PAST } \\
\text { VERBS }\end{array}$ & $\underset{(191)}{\star}$ & $\begin{array}{l}\text { ANSELMO AUGUSTO } \\
\text { FERNANDES COSTA }\end{array}$ & inglês & Médio \\
\hline & $\begin{array}{l}\text { Simple Past and } \\
\text { Present Perfect }\end{array}$ & 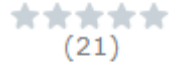 & Yana Ferreira & inglês & Fácil \\
\hline & $\begin{array}{l}\text { Simple Past Song } \\
\text { - Havana }\end{array}$ & 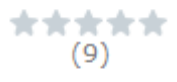 & $\begin{array}{l}\text { Adriane Luiza de } \\
\text { Andrade }\end{array}$ & $\begin{array}{l}\text { simple past } \\
\text { verbs }\end{array}$ & Fácil \\
\hline & Simple Past Verbs & $\underset{(6)}{t}$ & $\begin{array}{l}\text { Adriane Luiza de } \\
\text { Andrade }\end{array}$ & $\begin{array}{l}\text { simple past } \\
\text { verbs }\end{array}$ & Fácil \\
\hline & $\begin{array}{l}\text { Simple Past Verbs } \\
\text { pt } 2\end{array}$ & $\star(4)$ & $\begin{array}{l}\text { Adriane Luiza de } \\
\text { Andrade }\end{array}$ & $\begin{array}{l}\text { simple past } \\
\text { verbs }\end{array}$ & Fácil \\
\hline & Simple Past Verbs & $\underset{(11)}{\star \star \star \star ~}$ & $\begin{array}{l}\text { Adriane Luiza de } \\
\text { Andrade }\end{array}$ & $\begin{array}{l}\text { simple past } \\
\text { verbs }\end{array}$ & Fácil \\
\hline & Simple past verbs & $\frac{\hbar \star \hbar \star}{(9)}$ & Angela Musskopf & $\begin{array}{l}\text { Língua } \\
\text { Inglesa }\end{array}$ & Médio \\
\hline & $\begin{array}{l}\text { Review for Simple } \\
\text { Past }\end{array}$ & 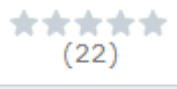 & Raquel Calsing & English & Médio \\
\hline & & $\mathbf{1}$ & Seguinte & & \\
\hline
\end{tabular}

Fonte: Os Autores (2021).

Ainda que esse ranking possa contribuir para a minha seleção dos REA, é necessário ressaltar que ele está disponível apenas para o Estudante; eu não consigo acessar essa informação no perfil de Professor.

Além disso, em função de o ranking estar disponível apenas para o perfil de Estudante, suponho que a atividade só será avaliada por outro docente quando este, no perfil de Estudante, atribuir nota ao material. Sem saber se as notas são de um colega docente ou de um aprendiz, questiono-me se um professor talvez não fique com dúvidas quanto às origens das avaliações e se, por conseguinte, essa situação não poderia implicar em descompassos. Afinal, estudos prévios na área de LA já confirmaram que os interesses e as preferências de estudantes e de professores de línguas podem ser bem divergentes em contextos de ensino na web (ver, por exemplo, LEFFA et al., 2017). Penso ser necessário considerar que alguns educadores podem julgar essas notas mais confiáveis se partirem de outros educadores, com formação pedagógica para avaliar atividades de ensino de línguas. Não discordo que as avaliações de Estudantes são, também, muito importantes para a reflexão sobre um conteúdo ou recurso a ser importado por um professor, mas argumento que a inclusão da avaliação de outros professores pode representar um aprimoramento de um processo de seleção mais colaborativo e em rede. Até este momento do meu percurso de exploração do sistema ELO, 
tenho a impressão de que a busca de materiais e a avaliação dos recursos do repositório, no perfil de Estudante, é mais rica em alternativas e potencialidades que aquelas disponíveis no perfil de Professor.

Ainda com relação às buscas e seleções de REA e materiais desenvolvidos por outros docentes, cabe sinalizar a falta de uma descrição resumida do conteúdo digital compartilhado. Apesar de os descritores e metadados do ELO em Nuvem atenderem aos interesses da área de ensino de línguas (COSTA; FIALHO, 2013), e de o processo de recuperabilidade dos REA ser complementado pelo sistema de ranqueamento das atividades, senti falta de um espaço para uma descrição resumida, em formato livre, do recurso ou do material. Produzida pelo próprio autor do recurso, essa breve descrição poderia garantir aos docentes um entendimento básico do material sem a necessidade de acessá-lo e de realizar a atividade proposta para entendê-lo. Acredito que, tal qual um abstract que otimiza a escolha pela leitura (ou não) de um artigo acadêmico na íntegra, esse breve resumo da atividade e seu objetivo, em poucas palavras, poderia facilitar a busca de recursos de um professor de IL2 no ELO em Nuvem.

Após as buscas, e com o ingresso nas atividades, acredito que ficam mais claros ao usuário os conceitos de Módulo e Atividade, a partir dos quais o ELO em Nuvem está organizado. Segundo Leffa (2012), o Módulo é o objeto de aprendizagem, ou a unidade mínima, que o professor usa para montar uma Atividade, que é composta de um ou mais Módulos. O Módulo representa uma parte; a Atividade, um todo. O usuário vai construindo saberes ao passo que vai realizando as tarefas (aquilo que o aprendiz faz) de cada Módulo e, nesse viés, realizando a Atividade. Ainda que uma Atividade possa ser composta por um único Módulo, creio que, no ELO, é mais comum o uso de vários Módulos para compor uma Atividade, conforme Figura 3:

Figura 3: Imagem do primeiro módulo (vídeo) da atividade verb to be simple past (f) ElO A) Estudante Atividades verb To be Simple Past

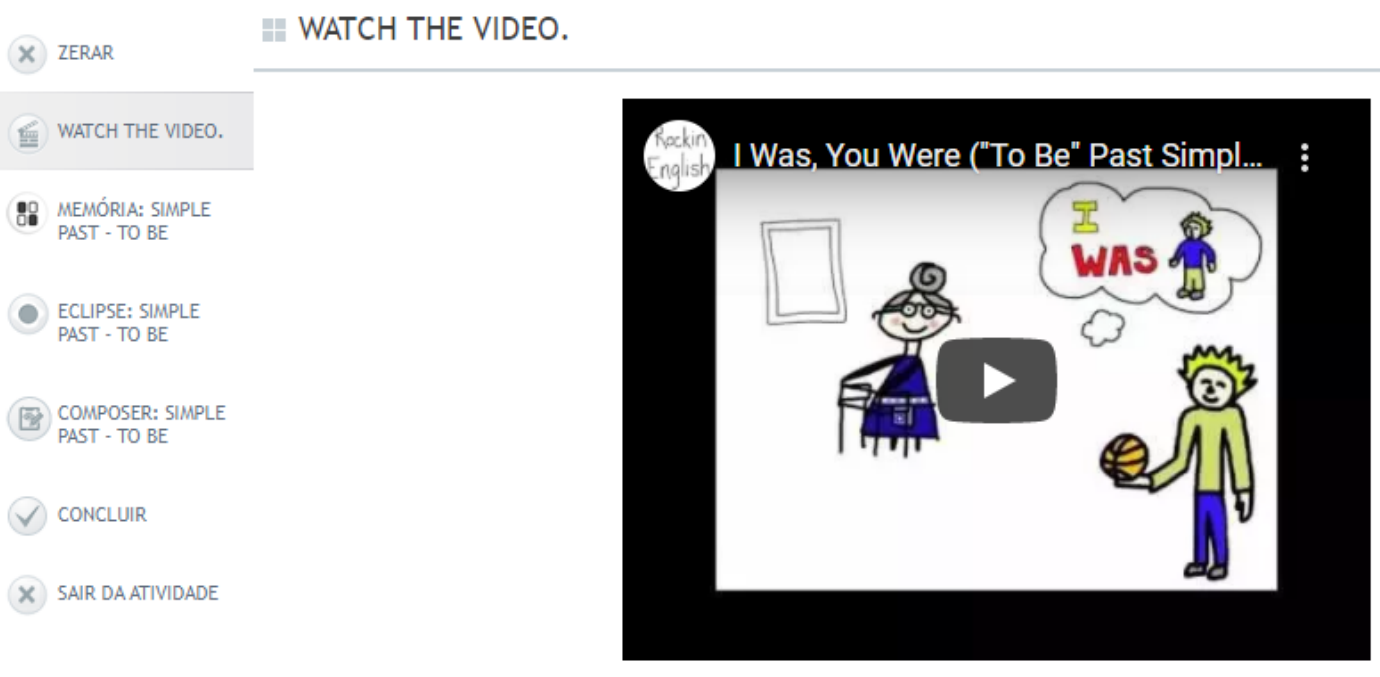

Fonte: Os Autores (2021). 
No menu à esquerda, estão organizados os vários Módulos que compõem a Atividade intitulada Verb To be Simple Past. A Atividade conta com 4 Módulos, sendo o primeiro Vídeo, e, na sequência, Jogo da Memória, Eclipse e Composer. Embora o Estudante possa realizar as tarefas fora da ordem sugerida, ele também pode seguir esse trajeto proposto, clicando na seta azul para avançar após a conclusão do Módulo. Sobre esse aspecto, vale lembrar que um dos objetivos do ELO é possibilitar aos docentes a (re)organização e a adaptação das Atividades a partir de seus vários Módulos, que podem ser empregados como peças de um jogo de montar, como em um jogo de Lego (LEFFA, 2016).

Caso eu queira, na condição de Professor, importar apenas o primeiro Módulo (Vídeo) da Atividade apresentada na Figura 3, por exemplo, e ignorar os demais Módulos, eu posso fazê-lo, e, então, seguir algum outro caminho pedagógico, produzindo minha Atividade em outra direção, com meus próprios Módulos e/ ou com aqueles importados de outros docentes. Acredito que essa potencialidade pode ser muito útil, no sentido de que, como professor posso constantemente reformular os materiais e conteúdos e criar novas Atividades, seja partindo dos diversos materiais já disponíveis no repositório do ELO em Nuvem, seja partindo de minhas próprias produções autorais.

Além de Módulo e Atividade, vejo como importante também o conceito de Curso. Enquanto a Atividade pode ser constituída por um ou mais Módulos, o Curso é constituído por uma ou mais Atividades. Assim como é possível a organização de Módulos em uma Atividade, também o é a organização de Atividades em um Curso. Esse recurso do ELO em Nuvem mostra-se pertinente para o professor de IL2 no que se refere à seleção e organização de material de ensino, incorporando Atividades produzidas por ele mesmo ou por outros professores. Em relação ao aluno, há um controle maior das Atividades que ele pode acessar, evitando que se perca dentro do sistema.

\subsection{A Curadoria Digital no ELO}

A partir do diário de bordo de um professor-curador de IL2, apresentamos aqui uma análise desse percurso dentro do ELO, na perspectiva dos 5 C's da curadoria digital (DESCHAINE; SHARMA, 2015). A apresentação será feita com cada $\mathrm{C}$ sendo analisado separadamente, mas entendemos que a curadoria do professor é um processo em constante movimento, cujas etapas são interdependentes e que, muitas vezes, podem ser confundidas. Nesse sentido, o que apresentamos a seguir é uma visão cristalizada de cada etapa do processo de curadoria digital de um professor de IL2.

Com relação ao primeiro passo da curadoria digital, a coleção (DESCHAINE; SHARMA, 2015), ou, então, coletar, no sentido de preservar e revisitar (CORREIA, 2018), podemos dizer que o ELO permite coletar atividades de outros autores e reutilizá-las em seu contexto de aplicação, fazendo as adaptações necessárias. Nesse sentido, criar uma coleção é possível de duas formas no ELO: 1) com a busca e/ou a importação de Módulos de Atividades de outros autores, 
que interessam ao professor-curador, para uso e/ou adaptação na perspectiva dos REA; e 2) com a criação de um Curso, salvando as Atividades que o professorcurador achou interessante para uso futuro, em uma espécie de pasta. Com relação a essa pasta, nosso único destaque se direciona à falta de um espaço para comparação e a catalogação especificamente no próprio ELO. Para essa prática, o professor poderia usar um bloco de notas ou um mural digital para fazer apontamentos. Desse modo, talvez o ELO pudesse adicionar um espaço para que o professor possa criar a sua coleção, com anotações pertinentes a cada atividade coletada. Caso contrário, ferramentas como o Padlet ou o Pinterest poderiam ser acopladas à prática de curadoria do professor. O lado negativo dessa "gambiarra" (SCHEIFER; REGO, 2020) é a de que os professores-curadores não usariam, talvez, a mesma ferramenta para tais anotações e análises. Caso fosse uma ferramenta nativa do ELO, poderíamos pensar, inclusive, em futuros compartilhamentos e anotações colaborativas.

A categorização (DESCHAINE; SHARMA, 2015), segundo passo do processo de curadoria digital, refere-se a categorizar, no sentido de comparar e generalizar os produtos (CORREIA, 2018). Essa etapa está relacionada à percepção de aspectos de coesão entre determinados recursos, ou seja, criar uma unidade de sentido para determinados REA, dentro da perspectiva de um conteúdo. Para a categorização no ELO, é preciso oferecer a possibilidade técnica de agrupar determinados recursos, como se fossem um livro didático ou uma unidade didática sobre determinado aspecto importante a ser trabalhado pelo professor com seus alunos. Dessa forma, verificamos que o ELO possibilita o passo da categorização quando permite que o professor crie determinado Curso com REA organizados de acordo com as necessidades do professor-curador. Vale lembrar que, no ELO, a designação Curso (com "c" maiúsculo) remete a um conjunto de Atividades, que pode ser enviado aos alunos via link, para fins de organização desses materiais em um curso (com "c" minúsculo), como discutimos no passo anterior, o da coleção. Ou seja, o que se possibilita na ferramenta Curso não é a estrutura de um curso exatamente, pois este carece de uma série de recursos necessários, como canal de comunicação entre alunos e professor, matrícula, gerenciamento dos professores ao acesso dos alunos etc., os quais podem ser supridos com o auxílio de outras ferramentas. Como um SAA, o ELO produz REA (BEVILÁQUA et al., 2017), os Cursos agregam Atividades e estas, por sua vez, agregam Módulos. Assim, também podemos entender que a própria criação de uma Atividade no ELO, com a importação de Módulos de vários outros professores, pode ser entendida como o passo de catalogação dentro do processo de curadoria. Vemos aqui, então, de forma clara, que essa possibilidade de catalogação na ferramenta já é uma prática corriqueira entre os professores autores e curadores de REA no ELO.

O terceiro passo da curadoria digital se refere à crítica (DESCHAINE; SHARMA, 2015), quer dizer, criticar no sentido de discriminar e avaliar os materiais de cada coleção (CORREIA, 2018). Ao defendermos a ideia de professor como curador, a crítica se aproxima muito da avaliação que o professor faz da implementação (LEFFA, 2008a) de um REA em determinada realidade. Assim, 
uma coleção categorizada para uma circunstância específica, por exemplo, pode ser criticada, no sentido de ponderar se um REA faz (ou fez) sentido para determinada coleção e contexto, antes ou após seu uso com algum grupo de alunos. Nessa perspectiva, acreditamos que o ELO oferece essa possibilidade; no entanto, também entendemos que esse passo depende muito mais do professor do que do próprio sistema. Essa etapa, no que toca ao SAA, poderia ser incrementada não só com avaliações de terceiros, indo além da apreciação com estrelas atribuídas pelos usuários no perfil Estudante, mas também incorporando o ponto de vista dos professores, de forma que pudessem comentar alterações que fizeram para seus respectivos contextos, entre outros aspectos. Dessa forma, a parte de crítica não seria feita apenas pelo professor, mas fomentada pelo coletivo de professores autores e curadores do ELO. Seja em um curso, seja nas atividades, as coleções no ELO podem ser atualizadas, cumprindo, assim, a possibilidade de se criticar e avaliar na perspectiva da curadoria sempre que necessário.

A conceituação (DESCHAINE; SHARMA, 2015), ou seja, a prática de conceituar, no sentido de reorganizar e reaproveitar, é o quarto passo do processo de curadoria digital (CORREIA, 2018). Nessa etapa, podemos fazer uma reorganização e reaproveitamento de REA que não foram usados para determinada coleção e que podem ser reutilizados em outra, de modo que novas conexões possam ser apresentadas. Após nossa análise, entendemos que o ELO possibilita a etapa da conceituação, pois permite a reorganização e, principalmente, o reaproveitamento de REA. Acreditamos que essa possibilidade se deva exatamente ao fato de que o ELO é um SAA que possibilita a criação de REA na perspectiva dos 4 R's: Reutilizar, Revisar, Remixar e Redistribuir (HILTON et al., 2010).

Por fim, a última etapa da curadoria digital se refere à circulação (DESCHAINE; SHARMA, 2015), isto é, circular no sentido de mostrar valor e tornar acessível (CORREIA, 2018). A circulação das coleções dos professores talvez seja o ponto mais fraco do ELO, tendo em vista que é preciso procurar, por meio dos descritores, as atividades produzidas e organizadas em determinadas coleções pelo professor. Parece-nos que a circulação se assemelha bastante a um mural virtual de curadoria, onde os professores poderiam ter suas páginas pessoais dentro do SAA, com a exposição das suas coleções, para que outros professores pudessem ver e se inspirar, inclusive para comporem suas próprias coleções. Como já colocamos em outro momento, ferramentas como o Padlet ou o Pinterest poderiam ser usadas como inspiração para o ELO possibilitar a criação de murais digitais de seus autores. Talvez pudéssemos incluir nesse mural de curadoria individual um espaço para comentários e troca de experiências, além de percepções sobre determinada coleção ou determinados REA que compõem a coleção. Assim, interpretamos que o ELO permite a circulação, no sentido de tornar acessível, mas poderia melhorar a forma de como isso é feito. 


\section{Considerações Finais}

Ampliando o debate iniciado por Araújo (2019), o estudo ora realizado não pretende esgotar as discussões sobre o assunto. Pelo contrário, almeja iniciar uma série de reflexões e pesquisas referentes à otimização de processos de curadoria digital de material didático para o ensino de IL2 por meio de tecnologias em rede, tais como o SAA ELO em Nuvem. Neste trabalho, portanto, tínhamos o objetivo geral de analisar as práticas de curadoria aplicadas ao sistema ELO. A partir desse propósito mais amplo, delimitamos três objetivos específicos, a saber: a) verificar a aplicabilidade dos 5 C's de curadoria digital (DESCHAINE; SHARMA, 2015) no ELO em Nuvem; b) averiguar potencialidades do ELO para facilitar a curadoria digital por parte do professor de IL2; e c) propor aprimoramentos e melhorias do sistema em questão no que tange à facilitação e otimização de práticas de curadoria entre docentes.

Quanto ao primeiro objetivo específico, identificamos que o ELO contempla, em alguma medida, os 5 C's de Deschaine e Sharma (2015). É possível realizar a curadoria de REA no ELO, embora alguns aspectos, em nossa perspectiva, possam ser aperfeiçoados, no sentido de tornar a curadoria digital um processo mais colaborativo e em rede. Do nosso ponto de vista, os princípios de Deschaine e Sharma (2015) representam um bom ponto de partida para a análise de processos de curadoria digital em ferramentas como o ELO. Todavia, poderiam levar em consideração, de forma mais eficaz, práticas colaborativas características da web 2.0 (FIALHO, 2011; LEFFA, 2016).

No que diz respeito ao segundo objetivo, verificamos que o ELO, por ser um SAA, possibilita a coleta, a categorização, a crítica, a conceituação e a circulação (DESCHAINE; SHARMA, 2015) de REA. Tais princípios de curadoria digital podem se dar por meio (1) da recuperabilidade dessas atividades com ajuda dos descritores, (2) da avaliação desses materiais com estrelas, e (3) da adaptação desses recursos quando necessário, entre outros aspectos.

No que tange ao terceiro objetivo específico, propusemos melhorias ao SAA ELO, todas na direção de uma possível curadoria digital mais colaborativa. Assim, destacamos nossas sugestões: ampliação de descritores e metadados para Professores, a fim de facilitar a recuperabilidade de REA; criação de murais digitais para a vitrinização das coleções dos professores-curadores; publicização de comentários de docentes e aprendizes sobre as atividades; e implementação de espaços para uma breve descrição das atividades elaboradas pelos docentes.

Por fim, salientamos que o presente estudo, apesar de enfocar o caso de professores de IL2, pode servir à reflexão sobre as práticas de curadoria digital de professores de todas as línguas. Ademais, apesar de enfocarmos, em nossa pesquisa, o ELO em Nuvem, entendemos que os $5 \mathrm{C}^{\prime}$ s da curadoria digital propostos por Deschaine e Sharma (2015) podem ser úteis na análise e na avaliação de outros SAA. Fazemos tais destaques porque tanto a curadoria digital quanto os SAA assumem relevância ímpar no ensino e na aprendizagem de línguas hoje, pela contribuição nas práticas docentes de (co)autoria de atividades 
e REA. A importância de ambos os tópicos é inegável na educação que temos no presente, e tende a manter-se no futuro que se desenha pós-pandemia e ERE.

Notas

1. De acordo com Leffa (2006a), a recuperabilidade diz respeito à facilidade de recuperar o material por meio de um sistema de metadados.

2. Diferente do restante do artigo, no qual é empregada a primeira pessoa do plural (nós) para respeitar a autoria coletiva do estudo, nesta seção será mantida a primeira pessoa do singular (eu), haja vista a matéria-prima desta parte do texto ser o registro em diário de bordo de um professor de IL2. Por esse mesmo motivo, na presente seção será mantido o uso de verbos no Presente do Indicativo.

3. A gamificação é um conceito cada vez mais popular no âmbito da Educação e da LA, e que está relacionado à presença de características de um jogo (em inglês, game) em contextos ou atividades na qual esses elementos não estavam postos $a$ priori (COSTA, 2016). A gamificação tem relação com o engajamento de pessoas para a resolução de problemas e tarefas, o que pode representar melhorias na construção de saberes dos aprendizes. O ELO em Nuvem oferece aos professores a possibilidade de gamificar módulos e atividades, isto é, incorporar elementos de jogos (como pontuação, ganho de medalhas e troféus, registro de recordes e presença em um ranking) às tarefas propostas.

\section{Referências}

ARAÚJO, N. M. S. Curadoria Digital: o importante papel do professor como curador de recursos educacionais digitais. In: FINARDI, K. R. et al. (Orgs.) Transitando e transpondo n(a) Linguística Aplicada. Campinas: Editora Pontes, 2019. p. 211-239.

BEVILÁQUA, A. F. Linguagens e tecnologias a serviço de uma Ética Maior: a produção de Recursos Educacionais Abertos na perspectiva dos Letramentos Críticos. 2017. Dissertação (Mestrado em Letras) - Programa de Pós-Graduação em Letras, Universidade Católica de Pelotas, Pelotas - RS, 2017.

BEVILÁQUA, A. F.; LEFFA, V. J.; COSTA, A. R.; FIALHO, V. R. Ensino de Línguas Online: um Sistema de Autoria Aberto para a produção e adaptação de Recursos Educacionais Abertos. Calidoscópio, São Leopoldo, v. 15, nº. 1, p. 190-200, 2017.

BINI, F. A. E. A crítica de arte e a curadoria. In: GONÇALVES, I. R.; FABRIS, A. (Orgs.). Os lugares da crítica da arte. São Paulo: Associação Brasileira de Críticos de Arte/Imprensa Oficial do Estado, 2005.

BRASIL. Ministério da Educação. Base Nacional Comum Curricular. Brasília, 2018.

CANTO, C. G. S. Reflexões de professores de inglês em formação sobre o uso de Webquests Interativas e Adaptáveis no processo de ensino e aprendizagem da língua inglesa. Revista Brasileira de Linguística Aplicada (online). Belo Horizonte, v. 16, no. 1, p. 25-49. 2016.

CEPEDA, M. E.; HORTIALES, E. S.; ROMERO, M. M. Objetos de aprendizaje: una forma de curaduría digital. In: COSTA, J. L. C. (Org.). Psicología y educación: presente y futuro. Madrid: Asociación Científica de Psicología y Educación (ACIPE), 2016. p.1937-1943.

CORREIA, A. P. As múltiplas facetas da curadoria de conteúdos digitais. Revista Docência e Cibercultura. Rio de Janeiro, v. 2, no. 3, p. 14-32, 2018.

COSTA, A. R. Professores de línguas "na" e "em" rede? Formação continuada de educadores para práticas abertas de (re)produção de materiais didáticos online. 
2016. Dissertação (Mestrado em Letras) - Programa de Pós-Graduação em Letras, Universidade Católica de Pelotas, Pelotas - RS, 2016.

COSTA, A. R.; FIALHO, V. R. A recuperabilidade em Objetos de Aprendizagem de Línguas: descritores em repositórios digitais. Domínios de Lingu@gem, Uberlândia, v. 7, nº. 1, p. 106, 2013.

COSTA, A. R.; BORSATTI, D. A.; GABRIEL, R. Exercícios no ensino de Línguas Estrangeiras em tempos de pandemia: opções de recursos tecnológicos. Trem de Letras, Alfenas, v. 8, p. 1-31, 2021.

DESCHAINE, M. E.; SHARMA, S. A. The Five Cs of Digital Curation: supporting twenty-first-century teaching and learning. Insight: A Journal of Scholarly Teaching, [on-line], v. 10, n. 1, p. 19-24, set. 2015.

FIALHO, V. R. Comunidades virtuais na formação de professores de Espanhol Língua Estrangeira a distância na perspectiva da Complexidade. Tese (Doutorado em Letras) - Programa de Pós-Graduação em Letras, Universidade Católica de Pelotas, Pelotas - RS 2011.

FONTANA, M. V. L.; FIALHO, V. R. Ferramentas de Autoria para Professores (FAPs): Entre batatas quentes e outras delícias. In: FONTANA, M. V. L.; FIALHO, V. R.; TREVISAN, A. L. (Orgs.). Línguas na EaD: Construção coletiva. Santa Cruz do Sul: Editora UNISC, v. 1, 2013, p. 88-103.

FREIRE, P. Pedagogia da autonomia: saberes necessários à prática educativa. 54. ed. Rio de Janeiro: Paz e Terra, 2016.

HILTON, J.et. al. The four R's of openness and ALMS analysis: frameworks for Open Educational Resources. Open Learning: the journal of open and distance learning, v. 25, n. 1, p. 37-44, 2010.

IRALA, V. B. A construção de objetos de aprendizagem na formação inicial: o vínculo ensino-extensão em uma perspectiva crítica. In: VETROMILLE-CASTRO, R.; HEEMANN, C.; FIALHO, V. R. (Orgs.). Aprendizagem de Linguas - a Presença na Ausência: CALL, Atividade e Complexidade. Pelotas: Educat, 2012, p. 209-240.

LEFFA, V. J. Nem tudo o que balança cai: Objetos de Aprendizagem no ensino de línguas. Polifonia, Cuiabá, v. 12, n. 2, p.15-45, 2006 a.

LEFFA, V. J. Uma Ferramenta de Autoria para o Professor: o que é e o que faz. Letras de Hoje. v. 41, n 144, p. 189-214, $2006 \mathrm{~b}$.

LEFFA, V. J. Como produzir materiais para o ensino de línguas. In: LEFFA, V. J. (Org.). Produção de materiais de ensino: prática e teoria. 2 ed. Pelotas: EDUCAT, 2008a. p. 15-41.

LEFFA, V. J. Malhação na sala de aula: o uso do exercício no ensino de línguas. Revista Brasileira de Linguística Aplicada, v. 8, nº. 1, p. 139-158, 2008b.

LEFFA, V. J. Sistemas de autoria para a produção de objetos de aprendizagem. In: BRAGA, J. (Org.). Integrando tecnologias no ensino de Inglês nos anos finais do Ensino Fundamental. São Paulo: Edições SM, 2012.

LEFFA, V. J. Uma outra aprendizagem é possível: colaboração em massa, recursos educacionais abertos e ensino de línguas. Trabalhos em Linguística Aplicada, Campinas, v. 55, nº. 2, p. 353-377, 2016.

LEFFA, V. J.; COSTA, A. R.; BEVILÁQUA, A. F.; FIALHO, V. R. Preferência dos estudantes na aprendizagem de línguas em três atividades do Moodle. Revista Brasileira de Linguística Aplicada, Belo Horizonte, v. 17, n. 1, p. 113-136, 2017.

MOURA, E. C. O artista-curador: propostas para além da criação estéticoconceitual. In: $22^{\circ}$ ENCONTRO NACIONAL DE PESQUISADORES EM ARTES 
PLÁSTICAS: ECOSSISTEMAS ESTÉTICOS, 2013, Belém. Anais [...] Belém: ANPAP/PPGARTES/ICA/UFPA, 2013. p.389-403.

NOBRE, A. M. J. F.; MALLMANN, E. M. Recursos Educacionais Abertos: transposição didática para transformação e coautoria de conhecimento educacional em rede. Indagatio Didactica, v. 8, n², jul 2016.

OKADA, A. Competências chave para coaprendizagem na Era digital: fundamentos, métodos e aplicações. Santo Tirso: Whitebooks, 2014.

ORLOWSKI, J. O dilema das redes (The Social Dilemma). Documentário. Netflix, 2020.

PAIVA, V. L. M. O. Inovações tecnológicas: o livro e o computador. In: VETROMILLECASTRO, R.; HEEMANN, C.; FIALHO, V.R. (Orgs). Aprendizagem de Linguas: CALL, Atividade e Complexidade. Uma homenagem aos 70 anos do Prof. Dr. Vilson José Leffa. Pelotas: Educat, 2012, p. 13-29.

PAIVA, V. L. M. O. Manual de Pesquisa em Estudos Linguísticos. São Paulo: Parábola. 2019.

PARISER, E. The Filter Bubble. New York: The Penguin Press, 2011.

SANTOS, A. I. Open educational resources in Brazil: state of the art, challenges and prospects for development and innovation. Moscow: UNESCO, 2011. Disponível em: $<$ http://www.iite.unesco.org/pics/publications/en/files/3214695.pdf $>$ Acesso em: 10 fev. 2016.

SANTOS, A. I. Recursos Educacionais Abertos no Brasil: o estado da arte, desafios e perspectivas para o desenvolvimento e inovação. São Paulo: Comitê Gestor da Internet no Brasil, 2013.

SCHEIFER, C. L.; REGO, M. C. S. R. Da redundância à gambiarra: reflexões para o ensino de línguas na Era do Digital. In: LEFFA, V. J.; FIALHO, V. R.; BEVILÁQUA, A. F.; COSTA, A. R. (Orgs.). Tecnologias e ensino de línguas: uma década de pesquisa em Linguística Aplicada. Santa Cruz do Sul: EDUNISC, 2020. p. 109128.

SILVA, T. M. Curadoria de Recursos Educacionais Digitais para o ensino de Língua Portuguesa: uma análise descritiva do processo curatorial dos repositórios Ambiente Athena, Currículo+ e MEC-RED à luz da Linguística Aplicada. 2019. 180 f. Dissertação (Mestrado em Linguística Aplicada) - Universidade Estadual do Ceará, Fortaleza, 2019.

UNESCO. Declaração REA de Paris em 2012. Paris, 20 jun. 2012. Disponível em: $<$ http://www.unesco.org/new/fileadmin/MULTIMEDIA/HQ/CI/WPFD2009/ Portuguese Declaration.html>. Acesso em: 29 nov. 2020.

VÍRSIDA, G. E. A. Una Experiencia de Lectura y Construcción de Conocimientos Culturales Utilizando el Sistema de Autoría "ELO". Informática na Educação: Teoria \& Prática, Porto Alegre, v. 9, nº. 1. p. 65-81, dez, 2006.

ZHANG, S. Teachers as Curators: Curating Authentic Online Content for Beginning and Intermediate CFL Learners. Journal of Chinese Teaching and Research in the U.S. p. 128-140. 2015. Disponível em: <https://lib.dr.iastate.edu/language_ pubs/95/>. Acesso em: 28 mai. 2021. 